\title{
Partial sine wave tracking dual mode control topology for a single- phase transformerless photovoltaic system
}

\author{
Koki OGURA ${ }^{1}$, Mohan Lal KOLHE ${ }^{2}$, Mutsuo NAKAOKA ${ }^{3}$
}

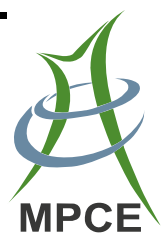

\begin{abstract}
A unique high efficiency photovoltaic (PV) system is presented. It uses partial sine wave tracking for a pulse-width modulation (PWM) boost converter as well as a full-bridge inverter. The boost converter and full-bridge inverter are connected via a compact intermediate film capacitor (i.e. non-smoothing DC link stage). PWM switching is activated by a dual mode control technique. In the proposed topology, simultaneous switching of both power conversion stages is avoided and therefore this increases the power conversion efficiency. The distinctive operating principles of these two power processing stages are discussed and analyzed with the experimental results for single-phase loading of the PV system.
\end{abstract}

Keywords Partial sine wave instantaneous tracking pulsewidth modulation (PWM) boost converter, Bypass diode, Dual mode control, High efficiency power conversion

CrossCheck date: 10 April 2018

Received: 8 September 2017/Accepted: 11 April 2018/Published online: 17 October 2018

(C) The Author(s) 2018

$\triangle$ Koki OGURA

ogura.k@ip.kyusan-u.ac.jp

Mohan Lal KOLHE

mohan.1.kolhe@uia.no

1 Kyushu Sangyo University, Fukuoka 813-8503, Japan

2 University of Agder, 4604 Kristiansand, Norway

3 University of Malaya, 50603 Kuala Lumpur, Malaysia

\section{Introduction}

Grid integration of solar photovoltaic (PV) systems is increasing exponentially. Building integrated PV (BIPV) system is intimately connected to the distributed power system network [1]. Most BIPV systems are single-phase inverters and these are operating with a maximum power point tracking (MPPT) mechanism using various methods focused on operating the system at the maximum power point [2]. The majority of the presented pulse-width modulation (PWM) techniques are using a continuous switching approach for the DC-DC boost converter and also for the single-phase sine wave inverter [3]. In the near future, the requirement will increase for PV power conditioning devices with higher efficiency, smaller size and of lower weight. Therefore, many different types of power conditioning devices and controller have been introduced for PV connection with the grid as well as for stand-alone power applications [4].

In this work, a novel topology is presented for the boost converter and single-phase inverter switching. These are not operating simultaneously and the switching frequencies of the power conditioning devices are reduced. Because of that, there is significant reduction in switching power losses and therefore the efficiency of the power conditioning devices is improved as well as their operational life. The presented switching techniques are implemented in the experimental setup to test their validity for off-grid loads (e.g. stand-alone PV applications). A single-phase sine wave PV system using a partial sine wave tracking PWM boost converter with an introduction of a bypass diode will then lead to a high efficiency of power conversion for a wide range of power settings with significant reduction in switching timings. The use of a small film capacitor to replace the DC link capacitor in middle of the both stages 
will definitely reduce the size and capacitance of the power converter. An experimental set-up is developed to test the proposed modulation and finds the actual power conversion efficiency to be comparable to the conventional type. Experimental results of this presented unique PV system are presented.

\section{Conventional PV system}

The conventional system configuration of the singlephase sine wave PV system is shown in Fig. 1a. This power circuit consists of a boost (step-up) DC-DC converter in addition to a full-bridge single-phase sine wave inverter with low-pass filter and load/utility AC power grid in parallel [5]. Its operating principle is shown in Fig. 1b. The boost converter in the first stage of power conversion is used for boosting a low DC voltage from the PV module array up to a constant output voltage (DC 350-400 V). The active power switch $\mathrm{SW}_{\mathrm{C}}$ in this boost converter always operates at a high frequency switching modulation to keep a constant output voltage in accordance with the fluctuating voltage from the solar photovoltaic generation source. In general, the boost converter stage causes switching losses and conduction losses because of high frequency PWM switching. Also the output side of this boost converter needs a bulky large-volumetric electrolytic DC capacitor. It is actually impossible to implement a smaller and lighter weight system. In addition to these, the bulky electrolytic DC capacitor provides lower reliability because of the power loss of the equivalent series resistance (ESR) based on the ripple current and degradation causing a short lifetime.

The full-bridge inverter in the second power processing stage is to make utility AC $200 \mathrm{~V}_{\text {rms }}$ using a sine wave carrier-based high frequency PWM. The active power switches $\left(\mathrm{SW}_{1}-\mathrm{SW}_{4}\right)$ in the full-bridge inverter cause switching and conduction losses because of high frequency switching sine wave carrier-based PWM. As a result, it uses continuous modulation in both stages and therefore the total system of this conventional type is not highly efficient because of these power losses.

\section{Proposed PV system}

The proposed partial sine wave instantaneous tracking PWM boost converter with a supported bypass diode $D_{\mathrm{b}}$ and a partial sine wave PWM full-bridge inverter with polarity changing are given in Fig. 2a. The power circuit in Fig. 2a comprises a partial sine wave tracking PWM boost converter, which is used for converting the input side DC link voltage to a partial sine wave $\mathrm{AC}$ absolute value in the first stage of power conversion. The full-bridge inverter with a low-pass filter in the second stage operates under a partial sine wave PWM with the function of polarity changing. Figure $2 b$ illustrates the unique operating principle with a dual mode control technique for this system. In this topology, it is not necessary to have constant DC output voltage between the first and second stages of power conversion and therefore an electrolytic DC capacitor bank is not required and is replaced by a small film capacitor.

In the first stage, the boost converter operates under a partial sine wave tracking PWM. In the second stage, the full-bridge inverter operates after the switching operation of the boost converter and it uses the absolute value of the sine wave output for the boost converter. The uniqueness of this topology is that it does not have simultaneous operation of the first and second stages of power conversion processing, in contrast to the conventional type. The total number of switching operation times can be reduced substantially by dual mode control techniques, and therefore the switching and conduction power losses of both power processing stages can be reduced significantly and this also increases the life of devices. Moreover, a small film capacitor in middle of both stages is used in place of the conventional electrolytic DC capacitor. The ESR of a film capacitor, which is used as a non-smoothing DC link, is very small given its compact size and it has extremely low power losses and longer life.

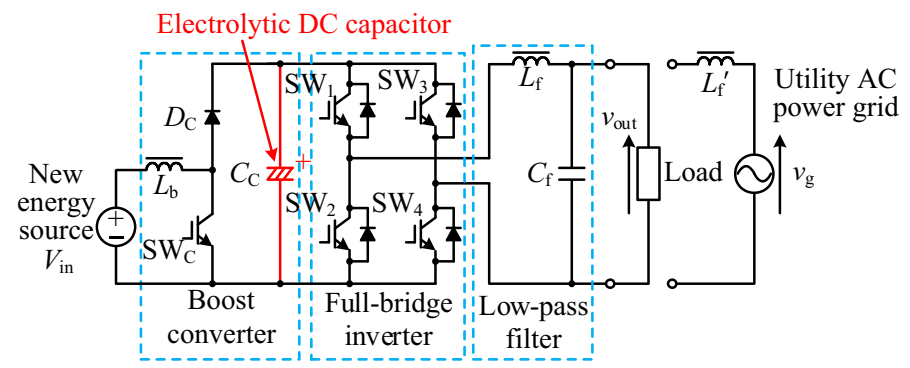

(a) Circuit configuration

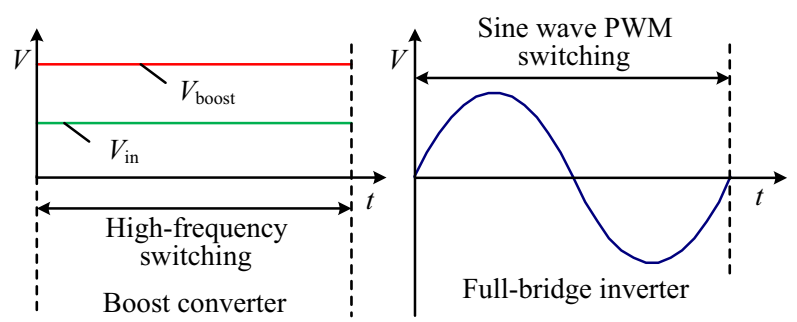

(b) Operating principle

Fig. 1 Conventional sine wave PV system 


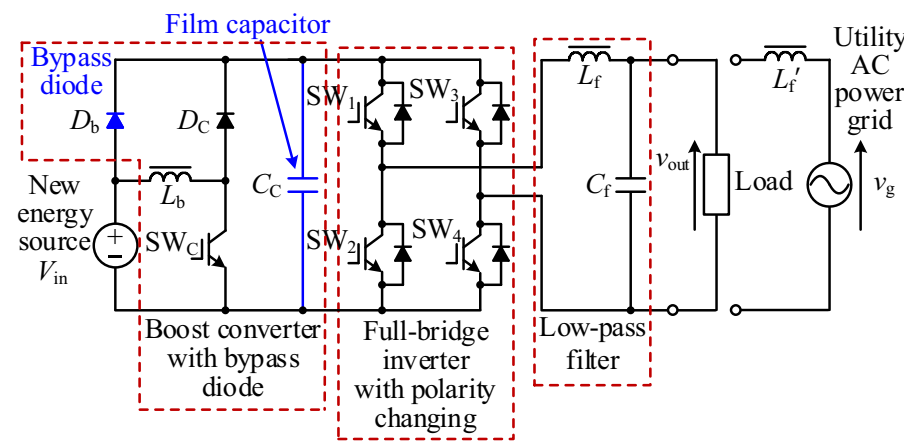

(a) Circuit configuration

Fig. 2 Proposed sine wave PV system

\section{Control schemes and unique features}

The control schemes for the presented single-phase sine wave PV system with dual mode control techniques in Fig. 2b are explained as follows.

1) Boost converter

Zone $\mathrm{I}_{\mathrm{cnv}}$ : PWM switching of boost converter with partial absolute sine wave tracking.

Zone $\mathrm{II}_{\mathrm{cnv}}$ : No PWM switching and partial assisted conduction mode of bypass diode.

2) Full-bridge inverter

Zone $\mathrm{I}_{\text {inv }}$ : No PWM switching of full-bridge inverter and polarity changing in the 2 nd half cycle.

Zone $\mathrm{II}_{\text {inv }}$ : PWM switching of full-bridge inverter with partial sine wave modulation around zero crossing area.

The boost converter duty ratio $D$ of $\mathrm{SW}_{\mathrm{C}}$ in Fig. 2a can be expressed with input voltage $V_{\text {in }}$ and output voltage $v_{\text {out }}$ as:

$D=1-\frac{1}{v_{\text {out }} / V_{\text {in }}}$

Using (1), the duty ratio $D$ can be specified from the input voltage $V_{\text {in }}$ and absolute value of desired sinusoidal output voltage $v_{\text {out }}$. Figure 3 illustrates the steady state boosted voltage ratio $\left(v_{\text {out }} / V_{\text {in }}\right)$ versus the duty ratio characteristics. This operating characteristic is used for the experimental setup.

Figure 4 shows the control block of dual mode sine wave modulation. When $V_{\text {in }}<\left|v_{\text {out }}\right|$, the boost converter operates for boosting and produces a partial sinusoidal pulse modulated waveform with the duty ratio characteristics of Fig. 3. The full-bridge inverter operates by comparing a triangular carrier signal with reference signal waveforms. The modulation index was designed with a value greater than 1 .

The PWM switching of the boost converter and fullbridge inverter are given in Fig. 5 and it can be seen that the switching cycle timings are reduced significantly. It can be observed from Fig. 5 that when $V_{\text {in }}<\left|v_{\text {out }}\right|$, then the $S W_{C}$ of the boost converter operates in high frequency PWM

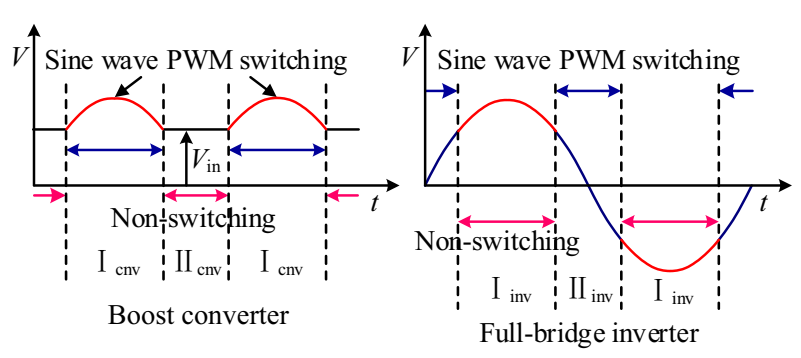

(b) Operating principle

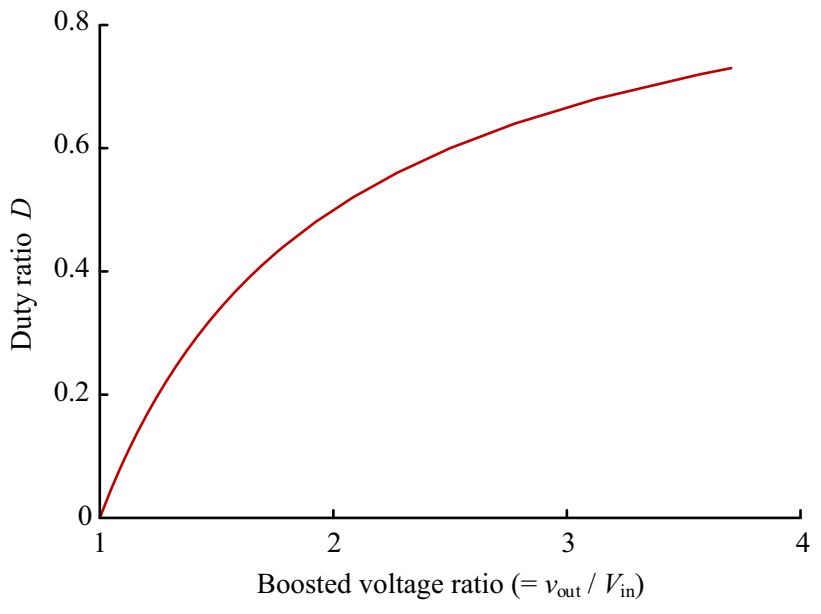

Fig. 3 Boosted voltage ratio vs. duty ratio characteristics of boost converter

switching mode. During this zone, it boosts the output voltage for generating a partial sine waveform using (1) and the switching of the full-bridge inverter is used for polarity changing (i.e. $\mathrm{SW}_{1} \& \mathrm{SW}_{4}$ operate in the 1 st half cycle and $\mathrm{SW}_{2} \& \mathrm{SW}_{3}$ operate in the 2 nd half cycle). When the input DC voltage $V_{\text {in }} \geq\left|v_{\text {out }}\right|$, the boost converter $\mathrm{SW}_{\mathrm{C}}$ does not function. In this zone, the input source current does not flow through inductor $L_{\mathrm{b}}$ and the freewheeling diode $D_{\mathrm{C}}$ but it flows through bypass diode $D_{\mathrm{b}}$ in Fig. 2a. The full-bridge inverter switches $\left(\mathrm{SW}_{1}-\mathrm{SW}_{4}\right)$ operate at high frequency PWM switching to produce a partial sine wave carrier when the boost converter switch $\mathrm{SW}_{\mathrm{C}}$ does not function. The switching operational times in both stages are reduced significantly compared to the conventional type and therefore switching and conduction power losses are decreased. As the full-bridge inverter operates at low or zero current value (i.e. Zone $\mathrm{II}_{\mathrm{inv}}$ ), the switching and conduction power losses of the full-bridge inverter stage also become low.

As a result, the given PV system can reduce the number of switching times and conduction power losses using these innovative dual mode control techniques with use of a compact intermediate film capacitor $C_{\mathrm{C}}$ and an assisted bypass diode $D_{\mathrm{b}}$. 


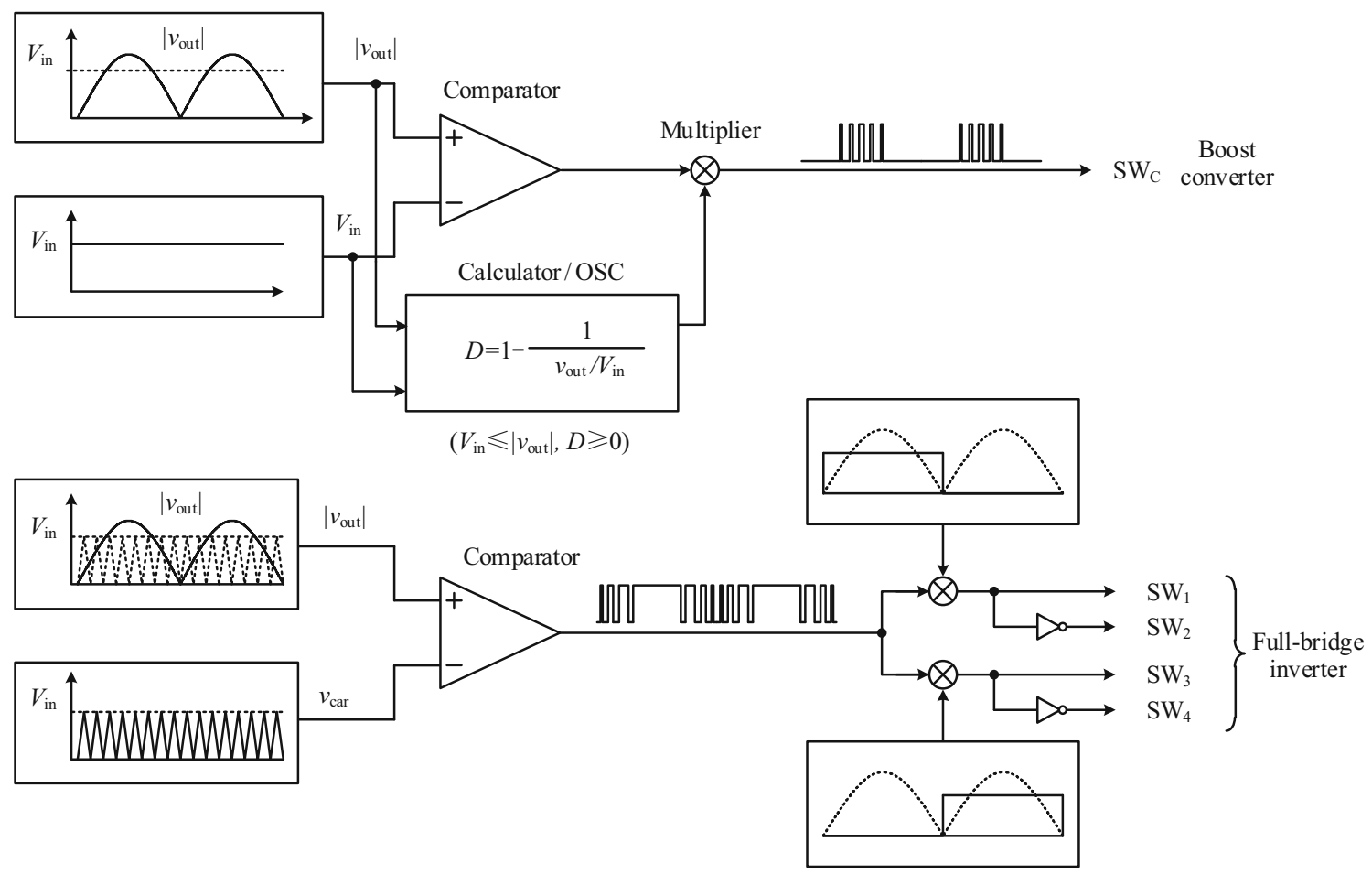

Fig. 4 Control block of dual mode sine wave modulation

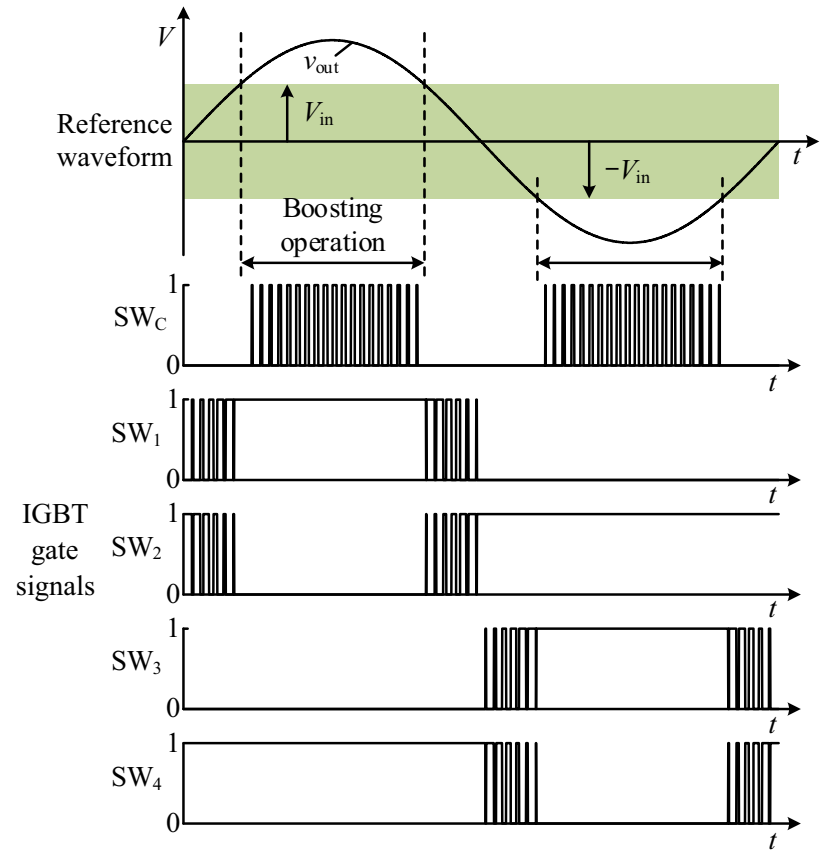

Fig. 5 PWM switching of boost converter and full-bridge inverter

\section{Experimental results and discussion}

The experimental circuit parameters and design specifications for the proposed PV system are listed in Table 1. In addition, Fig. 6 indicates the experimental set-up.
Table 1 Circuit parameters and design specifications

\begin{tabular}{lll}
\hline Item & Value & \\
\cline { 2 - 3 } & Conventional type & Proposed type \\
\hline$V_{\text {in }}$ & $160 \mathrm{~V}$ & $160 \mathrm{~V}$ \\
$v_{\text {out }}$ & $200 \mathrm{~V}_{\text {rms }}$ & $200 \mathrm{~V}_{\text {rms }}$ \\
$f_{\text {sw }}$ & $20 \mathrm{kHz}$ & $20 \mathrm{kHz}$ \\
$L_{\mathrm{b}}$ & $1 \mathrm{mH}$ & $1 \mathrm{mH}$ \\
$C_{\mathrm{C}}$ & $3900 \mu \mathrm{F}$ & $2.2 \mu \mathrm{F}$ \\
$C_{\mathrm{f}}$ & $10 \mu \mathrm{F}$ & $10 \mu \mathrm{F}$ \\
$L_{\mathrm{f}}$ & $1 \mathrm{mH}$ & $1 \mathrm{mH}$ \\
\hline
\end{tabular}

Figure 7 depicts the output voltage waveform of the boost converter (i.e. across intermediate film capacitor $C_{\mathrm{C}}$.

Figure 8 shows the current waveforms through the boost inductor $L_{\mathrm{b}}$. From these figures, the boost converter only operates when $V_{\text {in }}<\left|v_{\text {out }}\right|$.

The output voltage waveform of the full-bridge inverter (i.e. input side of low-pass filter) is given in Fig. 9. When the full-bridge inverter operates with the sine wave carrier-based PWM, the boost converter does not operate and the input current flows through an assisted bypass diode $D_{\mathrm{b}}$. When the boost converter operates under the partial sine wave tracking PWM, the full-bridge inverter switches do not operate.

The output load current and voltage waveforms of the proposed PV system are given in Fig. 10. In this 


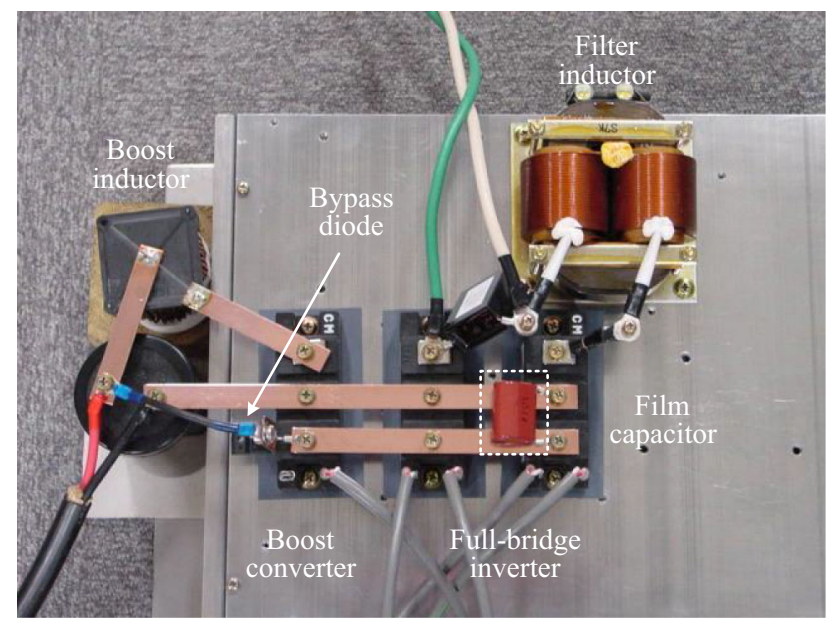

Fig. 6 Experimental set-up for PV system

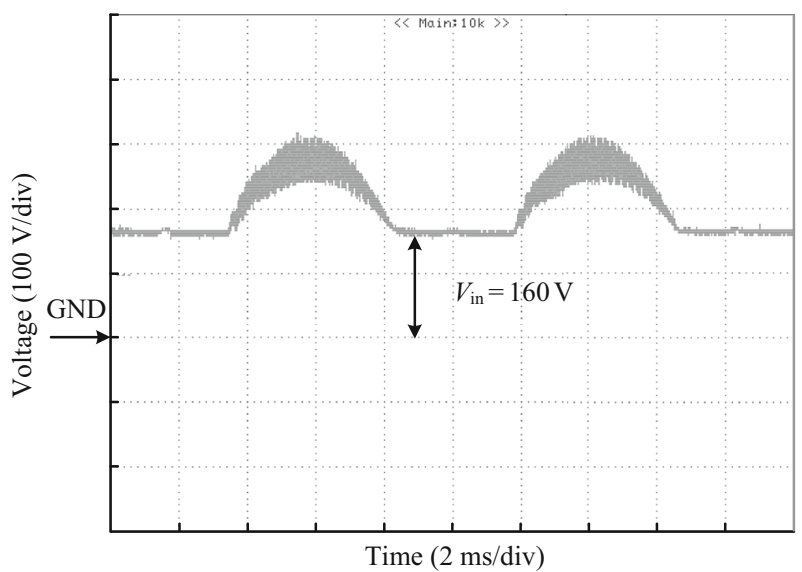

Fig. 7 Output voltage waveform of boost converter

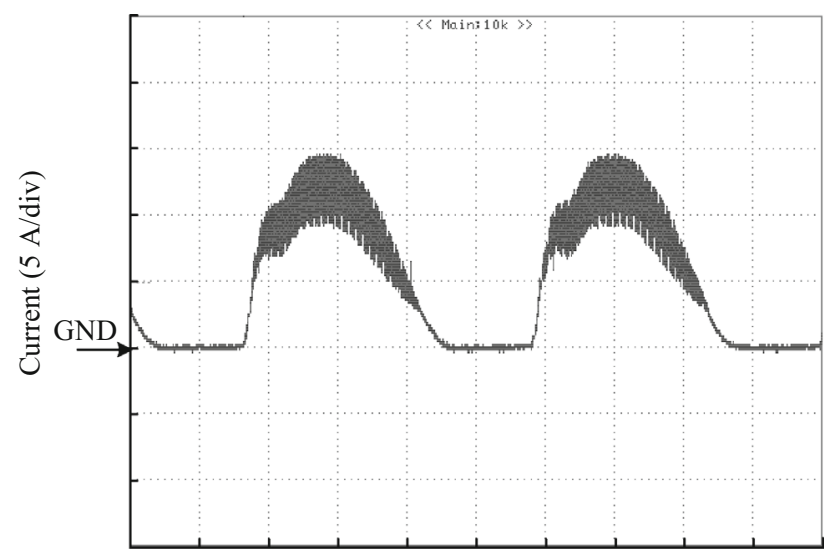

Time (2ms/div)

Fig. 8 Current waveform through boost inductor $L_{\mathrm{b}}$

experimental work, AC output current and voltage waveforms are produced as a high quality sine wave.

Figure 11 shows the harmonic orders vs. the harmonic contents characteristics. It can be seen that the actual

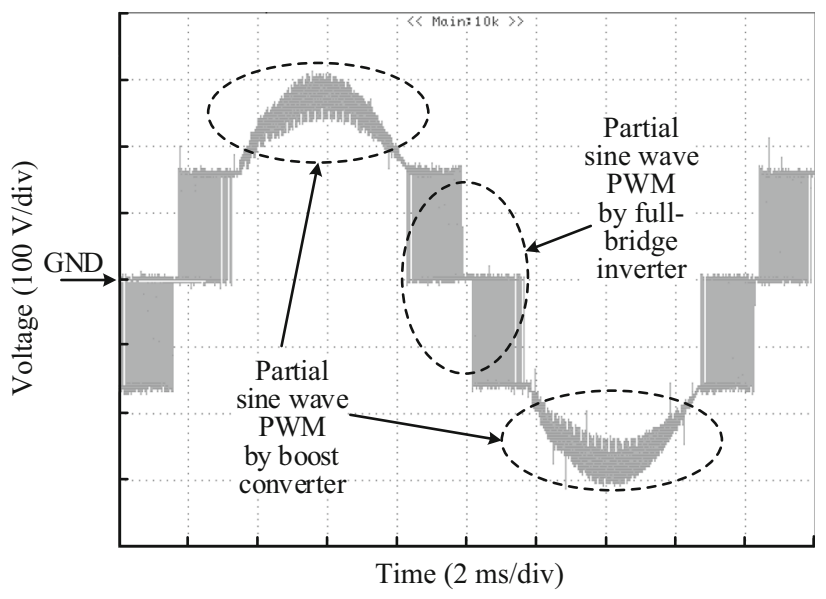

Fig. 9 Output voltage waveform of full-bridge inverter

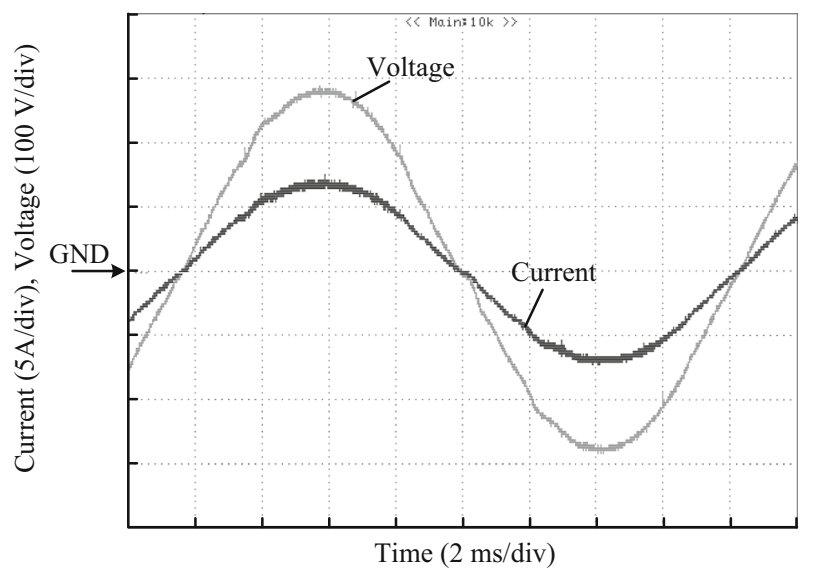

Fig. 10 Output load waveforms

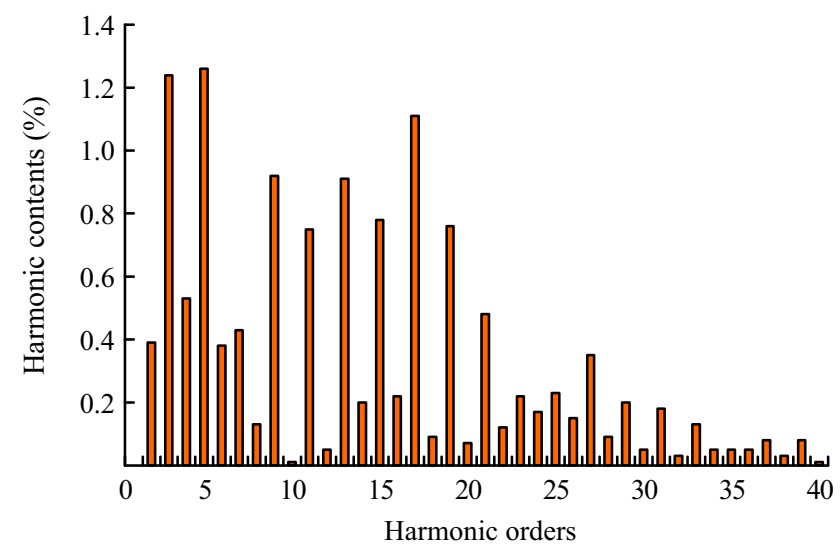

Fig. 11 Harmonics orders vs. harmonics contents characteristics

maximum harmonic content is less than $1.3 \%$. In this proposed topology, total harmonic distortion (THD) is coming in at $3.05 \%$. In the conventional type, THD is $0.94 \%$. 


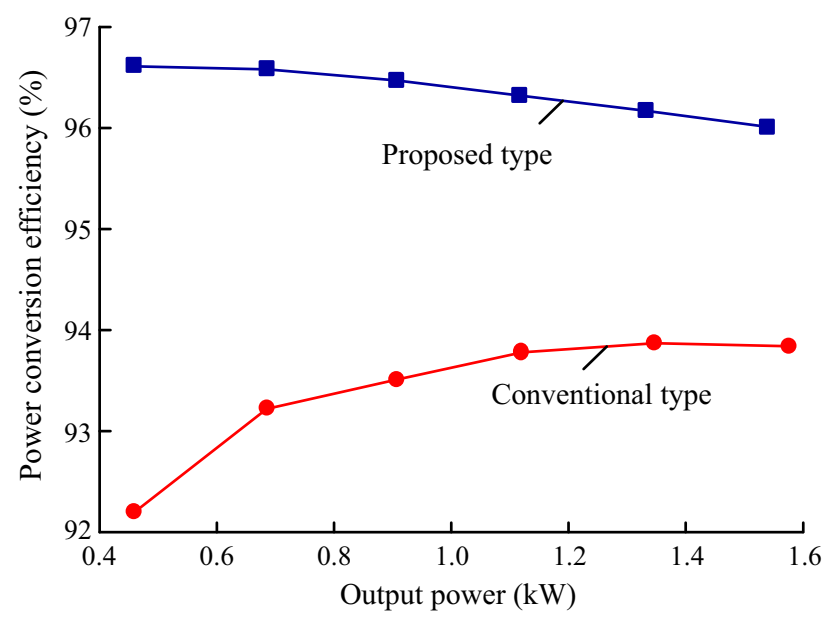

Fig. 12 Power conversion efficiencies

The power conversion efficiency of the presented and proposed power conversion systems is given in Fig. 12 and compared with the conventional type. It is seen that the operational efficiency of the proposed power condition devices is higher than the conventional type over the range of power outputs.

\section{Conclusion}

In this paper, the novel operating principle of a singlephase sine wave PV system with a partial sine wave tracking PWM boost converter has been presented and verified by experiment. During the operation of the fullbridge inverter, the bypass diode of the first stage power conversion helped in switching off operation of the boost converter. Therefore, the simultaneous switching of first and second power conversion stages was avoided and the power conversion efficiency was increased.
Open Access This article is distributed under the terms of the Creative Commons Attribution 4.0 International License (http:// creativecommons.org/licenses/by/4.0/), which permits unrestricted use, distribution, and reproduction in any medium, provided you give appropriate credit to the original author(s) and the source, provide a link to the Creative Commons license, and indicate if changes were made.

\section{References}

[1] Xiao H, Xie S, Chen Y et al (2011) An optimized transformerless photovoltaic grid-connected inverter. IEEE Trans Ind Electron 58(5):1887-1895

[2] Montoya DG, Paja CAR, Giral R (2016) Maximum power point tracking of photovoltaic systems based on the sliding mode control of the module admittance. Electr Power Syst Res 136:125-134

[3] Barater D, Lorenzani E, Concari C et al (2016) Recent advances in single-phase transformerless photovoltaic inverters. IET Renew Power Gener 10(2):260-273

[4] The National Institute of Standards and Technology (2016) Power conditioning systems for renewables, storage, and microgrids. http://www.nist.gov/el/smartgrid/powercon.cfm. Accessed 21 August 2017

[5] Hwu KI, Jiang WZ (2015) Time-sharing PWM control scheme for isolated multi-output DC-DC converter. IET Electron Lett 51(18):1446-1447

Koki OGURA is an associate professor at Department of Electrical Engineering, Kyushu Sangyo University. His research interests include circuit design and integration of high-frequency soft switching power converters, power electronics applications in home appliances, transportation and renewable energy systems.

Mohan Lal KOLHE is a professor in electrical power engineering with focus in smart grid and renewable energy at Faculty of Engineering and Science, University of Agder. His research interests include the smart grid, grid integration of renewable energy systems, home energy management system, solar and wind energy engineering.

Mutsuo NAKAOKA is a visiting professor at Power Electronics and Renewable Energy Research Laboratory, University of Malaya. His research interests include applications and developments of power electronics circuits and systems for industrial electronics and home appliances. 